\title{
Small Optical Components for the National Ignition Facility
}

\author{
J. R. Taylor, R. Chow, H. D. Bissinger
}

This article was submitted to Optical Society of America Optical Fabrication and Testing Topical Meeting Quebec City, Canada June 18-22, 2000

\section{February 15, 2000}

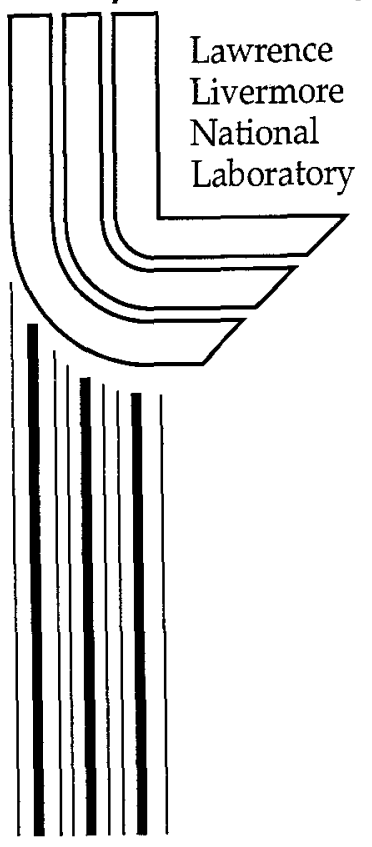




\section{DISCLAIMER}

This document was prepared as an account of work sponsored by an agency of the United States Government. Neither the United States Government nor the University of California nor any of their employees, makes any warranty, express or implied, or assumes any legal liability or responsibility for the accuracy, completeness, or usefulness of any information, apparatus, product, or process disclosed, or represents that its use would not infringe privately owned rights. Reference herein to any specific commercial product, process, or service by trade name, trademark, manufacturer, or otherwise, does not necessarily constitute or imply its endorsement, recommendation, or favoring by the United States Government or the University of California. The views and opinions of authors expressed herein do not necessarily state or reflect those of the United States Government or the University of California, and shall not be used for advertising or product endorsement purposes.

This is a preprint of a paper intended for publication in a journal or proceedings. Since changes may be made before publication, this preprint is made available with the understanding that it will not be cited or reproduced without the permission of the author.

This report has been reproduced directly from the best available copy.

Available electronically at http://www.doc.gov/bridge

Available for a processing fee to U.S. Department of Energy

And its contractors in paper from

U.S. Department of Energy

Office of Scientific and Technical Information

P.O. Box 62

Oak Ridge, TN 37831-0062

Telephone: (865) 576-8401

Facsimile: (865) 576-5728

E-mail: reports@adonis.osti.gov

Available for the sale to the public from

U.S. Department of Commerce

National Technical Information Service

5285 Port Royal Road

Springfield, VA 22161

Telephone: (800) 553-6847

Facsimile: (703) 605-6900

E-mail: orders@ntis.fedworld.gov

Online ordering: http:/ / www.ntis.gov/ordering.htm

\section{OR}

Lawrence Livermore National Laboratory

Technical Information Department's Digital Library

http: / / www.llnl.gov/tid/Library.html 


\title{
Small optical components for the National Ignition Facility
}

\author{
John R. Taylor, Robert Chow, Horst D. Bissinger \\ Lawrence Livermore National Laboratory, P. O. Box 808, L-487, Livermore, CA 94550 \\ 925-423-4438, fax 925-422-1210, taylor10@llnl.gov, chow3@1lnl.gov, bissinger1@llnl.gov
}

\begin{abstract}
The National Ignition Facility will be the largest laser system in the world. The facility, currently under construction, requires over 25,000 small optical components. The small-optics requirements and latest procurement strategy will be presented.

(C) 1999 Optical Society of America

OCIS codes: (140.0140) Lasers and laser optics; (350.2660) Fusion
\end{abstract}

\section{Introduction}

The National Ignition Facility (NIF) will be the largest laser system in the world when fully operational. The NIF facility will consist of 192 beam-lines delivering a total of $1.8 \mathrm{MJ}$ in a 20-nsec pulse of $351 \mathrm{~nm}$ light to a $600 \mu \mathrm{m}$ diameter target. NIF is a cornerstone of the DOE's Stockpile Stewardship and Management Program and will be used to study fusion ignition.

A laser beam-line starts with the Injection Laser System (ILS) which is used to inject up to $3 \mathbf{J}$ of energy at $1053 \mathrm{~nm}$ into each main amplifier chain. At this point the beam is enlarged to a rectangular beam of $37 \times 37 \mathrm{~cm}^{2}$ for transport through the main amplifier, the power amplifier, and the delivery system to the final optics where the frequency is converted to the third harmonic and the beam is focused toward the target. The energy from all 192 beam-lines must arrive at the target simultaneously with well-controlled wavefronts. Approximately 7,500 meter-class optical components are required to amplify, transport, frequency convert, and focus the full size beam [1]. In addition to the large optics, there are over 25,000 optics, called "small optics" by comparison to the meter-class optics, that are required for the ILS and the supporting alignment and diagnostic systems [2]. Although there are many different types of small optics, almost all are less than $152 \mathrm{~mm}$ in size. Recent changes in the schedule and deployment strategy for the special laser equipment have resulted in a revised plan for procuring the small optics.

\section{NIF Small Optics}

The ILS consists of the Pre-Amplifier Module (PAM), a relay telescope, the Pre-Amplifier Beam Transport System (PABTS), the Injection System, and the Input Sensor. There are approximately 7,056 optics in the ILS system not including the Input Sensor which is a diagnostic system described later. The PAM amplifies light from the master oscillator by over ten orders of magnitude and enlarges the size of the beam to $30 \times 30 \mathrm{~mm}^{2}$. A four-element relay telescope expands the beam to $45 \times 45 \mathrm{~mm}^{2}$ and relays the pupil into the PABTS. PABTS consists of an isolation system to attenuate backward propagating beams, a series of beamsplitters that divides the beam into four beams of equal magnitude, adjusts the beam path-length and timing to the target, and relays the pupil by means of a vacuum relay telescope to the injection telescope. The injection telescope and transport mirrors inject the beam into the main amplifier chain at the center of the transport spatial filter. From there, the beam is enlarged to full size and amplified and transported to the target through the large optics. The ILS subsystems are listed in Table 1 along with the number of optics and how the optics will be procured.

Table 1. Small optics for ILS

\begin{tabular}{lcl}
\hline ILS Optical Subsystem & Quantity of Optics & Procurement Method \\
\hline PAM & 2736 & Integrated package \\
PABTS Telescopes & 1152 & Integrated package \\
PABTS Individual Optics & 2064 & Mounted optics \\
Faraday Rotators & 240 & Individual optics \\
Laser Rods & 144 & Individual optics \\
Injection \& $1 \omega$ windows & 144 & Individual optics \\
Injection Telescopes & 576 & Integrated package \\
\hline
\end{tabular}


The input sensor package is located at the end of the PAM and provides a feedback for the laser alignment system to diagnose the beam quality delivered by the PAM. It also provides a CW beam for alignment in place of the PAM laser. For diagnostics of the full size beam, a diagnostic beamsplitter is used to pick off $0.25 \%$ of the light after the beam has passed through the main amplifier four times and the power amplifier two times. A relay system delivers this light and a reflection from the final optics to the output sensor package (OSP). The OSP provides near and farfield images, wavefront information, energy, pulse shape and timing of the beam being sent to the target. There are additional small optics for illuminators, light sources, and reticles in the main laser spatial filters and behind key large optics.

Additional small optics are required for the diagnostic systems in the target area. The target area sensor (TAS), located near the center of the target chamber, is used for beam alignment. The chamber center-reference system (CCRS) views the center of the target chamber from the outside and provides positioning reference for TAS. Two systems are inserted into the target chamber for evaluation and diagnostics. The final optics are evaluated by the final-optics damage inspection system (FODI). Time of each beam-line can be measured precisely with the pulse synchronization detector (PSD).

Detailed beam-line evaluation is performed, when needed, by the precision diagnostics system (PDS) that uses a roving mirror assembly to select the specific beam to be evaluated. The PDS can image the beam in the near and far field, provides an alignment laser for aligning the transport mirrors, and performs diagnostics. The large optics in the main laser can be inspected for damage by means of the large optics damage inspection system (LODI) which is part of the PDS.

The alignment and diagnostic subsystems utilize about 18,425 optics as listed in Table 2 along with the number of small optics and the method for procurement.

Table 2. Small optics for alignment and diagnostics

\begin{tabular}{lcl}
\hline Alignment \& Diagnostic Optical Subsystem & Quantity of Optics & Procurement Method \\
\hline ILS Input Sensor & 2352 & Integrated package \\
Output sensor & 5376 & Integrated package \\
$1 \Omega$ Alignment Relay Optics & 1776 & Mounted optics \\
$1 \Omega$ Diagnostic Optics & 2112 & Mounted optics \\
Main Laser Alignment Light Sources & 3072 & Mounted optics \\
Illuminators - Reticles & 1296 & Mounted optics \\
$3 \Omega$ Energy Diagnostic & 1944 & Integrated package \\
Chamber Center Reference System & 30 & Individual optics \\
PDS Large Optics & 50 & Individual optics \\
PDS, LODI, FODI, Pulse Sync. & 417 & Mounted optics \\
\hline
\end{tabular}

\section{Specifications for Small Optics}

Many of the small optics must meet high positioning and performance requirements. Their tolerances and specifications are critical and in some cases challenge the optics industry. Where possible, commercially available optics have been selected. When build-to-print optics are required, ISO 10110 standards have been followed. These standards allow design requirements to be precisely defined in most cases. There is also a requirement that test data be submitted electronically for build-to-print optics.

The wavefront error for individual optics is derived from the error budget permitted for the laser beam using system models. Specification for surface form as well as transmitted and reflected wavefront errors are applied. In particular, the RMS gradient of the wavefront error (RMS Gradient) is specified because it has the best correlation with the focusability of the beam. Because of the relationship between the spatial frequency of a given error and its effect on laser system performance, spatial filtering is applied $(>2 \mathrm{~mm}$ ). This approach is outside the framework of ISO 10110. Clarifications are provided where necessary. In addition, the surface form and wavefront specifications apply after coating in the use environment. 
Coatings required for small optics include anti-reflection (AR), high reflecting (HR), and polarizing (POL) coatings. All three types are designed for $1053 \mathrm{~nm}$ beams and the first two types for $351 \mathrm{~nm}$ beams. Spectral requirements (reflectance and/or transmittance for these wavelengths at specific polarizations, angle of incidence, and environment conditions) and laser damage thresholds are specified.

There are several concerns associated with the demanding requirements and small optics specifications: (1) the optical specifications are in the relatively new ISO 10110 standard format with associated NIF clarifications; (2) in some cases, the suppliers will have to be carefully selected to be sure that their manufacturing and test capabilities meet the requirements; and (3) the requirement to submit electronic test data is not standard and may present an additional hurdle to suppliers who might otherwise be capable of delivering acceptable optics.

\section{Procurement Strategy}

It is recognized that industry support is needed at a high level in order to build NIF. The project has just completed an effort to rebaseline the cost and schedule. The procurement strategy for small optics has moved toward a plan to buy the ILS and diagnostic subsystems at as high a level as possible. As described in Tables 1 and 2, small optics will be purchased either individually, in mounts, or in integrated packages. Approximately $55 \%$ of the optics will be supplied in integrated packages and will be the responsibility of the integration subcontractor. Mounted optics, about $35 \%$ of the total number of small optics, and the remaining individual optics will be grouped together in common types to minimize the number of procurements. Mounted optics are a simple level of integration where the optic is mounted, tested interferometrically in the mount, and delivered in clean condition packaged in cleanroom protection ready to be installed in NIF.

In order to ensure communication during the integration contracting process, optics metrology and quality assurance requirements have been established. This involves the following general principles: (1) identify and focus on the quality of the optics that influence system the most; (2) identify optics that have a limited source of supply; (3) monitor the integrator's procurement, quality assurance and metrology plans; (4) witness acceptance testing for sensitive optics by the integrator; and (5) integrator supplies inspection/test data on optical components in electronic form. Optical component testing as well as subsystem level testing will be used to ensure that NIF requirements are maintained. At this point, several first article subsystems have been ordered from integration subcontractors.

\section{Summary}

A large number of NIF small optics will be required over the next few years. A new procurement strategy will decentralize the procurement of over half of these optics through the purchase of integrated packages. More effort in the procurement process for these integrated packages results in reduced effort in procuring and testing individual optical components and should better utilize the expertise of the optics industry in the NIF deployment effort.

\section{References}

1. P. A. Baisden, "National Ignition Facility (NIF) program update," in Optical Fabrication and Testing,

A. Lindquist, M. Piscotty, Same Conference, (Optical Society of America, Washington, D.C., 2000)

2. H. D. Bissinger, "NIF Small Optics Group", http://lasers.llnl.gov/lasers/nif/optics-summit

This work was performed under the auspices of the U.S. Department of Energy by Lawrence Livermore National Laboratory under contract No. W-7405-Eng-48. 